\title{
Flexural Strength of RC Beam Strengthened by Partially De-bonded Near Surface-Mounted FRP Strip
}

\author{
Soo-yeon Seo ${ }^{1), *}$, Ki-bong $\mathrm{Choi}^{2)}$, Young-sun Kwon ${ }^{3)}$, and Kang-seok Lee ${ }^{4)}$
}

(Received January 13, 2016, Accepted February 17, 2016, Published online March 11, 2016)

\begin{abstract}
This paper presents an experimental work to study the flexural strength of reinforced concrete (RC) beams strengthened by partially de-bonded near surface-mounted (NSM) fiber reinforced polymer (FRP) strip with various de-bonded length. Especially, considering high anchorage capacity at end of a FRP strip, the effect of de-bonded region at a central part was investigated. In order to check the improvement of strength or deformation capacity when the bonded surface area only increased without changing the FRP area, single and triple lines of FRP were planned. In addition, the flexural strength of the RC member strengthened by a partially de-bonded NSM FRP strip was evaluated by using the existing researchers' strength equation to predict the flexural strength after retrofit. From the study, it was found that where de-bonded region exists in the central part of a flexural member, the deformation capacity of the member is expected to be improved, because FRP strain is not to be concentrated on the center but to be extended uniformly in the de-bonded region. Where NSM FRP strips are distributed in triple lines, a relatively high strength can be exerted due to the increase of bond strength in the anchorage.
\end{abstract}

Keywords: flexural strength, partially de-bonded NSM FRP strip, de-bonded length, anchorage capacity, deformation capacity, single and triple lines of FRP.

\section{Introduction}

The retrofit of concrete structures using fiber reinforced polymer (FRP) is rooted in the retrofit using reinforcements in Europe in the 1950s. Afterward, externally bonded retrofit (EBR) which is a method of bonding a sheet or plate shaped FRP to the surface of concrete, has been widely used with development of FRP materials. Near surface-mounted retrofit (NSMR) method is currently being applied to sites.

Accordingly, ACI 440 (2002) and fib code (2001) have reflected the contents of NSMR for their utilization in design. However, the existing studies on NSMR of FRP members have produced only very limited outcome. That is why it is necessary to conduct a study on the systemization of construction method and the completion of design method.

NSMR that strip-typed FRP is vertically mounted can increase retrofit efficiency, because it can relatively facilitate

\footnotetext{
${ }^{1)}$ Department of Architectural Engineering, Korea National University of Transportation, Chungju, Korea. *Corresponding Author; E-mail: syseo@ut.ac.kr

${ }^{2)}$ Department of Architectural Engineering, Gachon University, Seongnam, Korea.

${ }^{3)}$ Jaeshin CTNG, Co., Ltd., Seoul, Korea.

${ }^{4)}$ Department of Architectural Engineering, Cheonnam National University, Gwangju, Korea.

Copyright $($ The Author(s) 2016. This article is published with open access at Springerlink.com
}

grooving and increase bond area. However, as a groove needs more than a certain depth, there are, comparatively, limits to applying this method to members with thin cover concrete. In contrast, the bond area in embedding rectangular or round shaped FRP is comparatively smaller compared with plate typed FRP. However, rectangular or round shaped FRP needs to make a relatively wide groove instead of making a deep groove. Thus, that is easy to apply to members with thin cover concrete.

According to the result of the existing studies, the method of making a narrow and deep groove in a concrete member and embedding FRP strip in the groove vertically has higher retrofit efficiency compared with a method using NSMR using a round or rectangular bar, because the bond area of FRP plate inserted in a groove is more. Besides, the former's grooving work is easier than the latter's.

This study intends to conduct an experimental study on the retrofit effect of NSMR using a FRP strip and the anchorage effect of the FRP strip in reinforced concrete (RC) member. Especially, considering high anchorage capacity at end of a FRP strip, this study intends to set up a de-bonded region at a central part and to study a behavior according to a change in a de-bonded length. In order to check the improvement of strength or deformation capacity when the bonded surface area only increased without changing the FRP area, two cases of FRP line were planned: an installation in a line for beam section; a distributed installation in triple line. The sectional areas of FRP in these two cases are almost the same.

Besides, this study intends to evaluate the bond strength of a partially de-bonded flexural member, based on the existing 
researchers' strength equation for calculation of bond strength.

\section{Previous Researches}

The superiority of the NSMR that forms a groove on concrete within the cover concrete and then filling an FRP for reinforcement is known from the flexural experiment for a highway bridge carried out by Nanni (2000). In the study, for bonding a carbon FRP (CFRP) plate on the external surface, the CFRP plate peeled off at the final step, but for embedding a bar shaped CFRP in cover concrete, the CFRP got a tensile fracture, and the contributions to overall resistance were 17 and $29 \%$, respectively, so it turned out that the NSMR was more effective.

After that, several researchers performed bond test about NSM FRP (Jose and Barros 2007; Ceroni et al. 2012; AlMahmoud et al. 2012; Lee et al. 2013; Ali et al. 2008; Seracino et al. 2007a, b; Seo et al. 2013) and found that it is effective in acquiring higher bond capacity. Among them, a few studies (Ali et al. 2008; Seracino et al. 2007a, b; Seo et al. 2013) about both bond theory and bond strength equation of NSM FRP strip have been performed based on the previous bond test results. As a recent research, Seo et al. (2013) performed a bond test on NSM FRP plate with various bonded lengths as well as number of shear keys. From the test result, they found that the member strengthened by NSMR has almost 1.5 times higher bond strength than that by EBR.

From a flexural test of RC beam strengthened by NSM FRP retrofit (EI-Hacha and Rizkalla 2004; Hassan and Rizkalla 2003; Sharaky et al. 2014), the NSMR has a much higher retrofit capacity than EBR, and presented that especially the case in which the FRP plate was vertically inserted in the member for reinforcement exhibits the most excellent performance. As a recent research, Rezazadeh and Barros (2015) performed an experimental work for the beams retrofitted by pre-stressed CFRP whose shape is very thin. In the manner of construction labor, the groove for vertical embedment of a thin FRP strip is little bit narrower and deeper than that for square or round one. The work for making the narrow groove is relatively easy and the FRP can be easily fixed into the groove during the curing of epoxy. And the rigidity of the FRP for vertical embedment is relatively high for vertical direction so that it is possible to reduce the vertical deflection of the FRP by self-weight during the construction. In case of the strengthening of a long member, an excessive vertical deflection of FRP material may occur during the construction and it can give a negative effect in inserting the FRP into the groove and fixing it. Considering this merit, several researchers (Ali et al. 2008; Seracino et al. 2007a, b; Seo et al. 2013; Rezazadeh and Barros 2015; Yost et al. 2007; Seo 2012) have performed various experimental and analytical works about the NSM FRP retrofit to find both the bond capacity and a proper design process.

In spite of the excellence of NSM FRP retrofit, there is a possibility of a reduction of energy and displacement ductility or a bond failure of NSM FRP (Yost et al. 2007; Lorenzis et al. 2000).
Chahrour and Soudki (2005) investigated the flexural behavior of RC beams strengthened with end-anchored partially bonded CFRP strips through an experimental and analytical study. The experimental results revealed that endanchored partially bonded CFRP strips significantly enhanced the ultimate capacity of the control beam and performed better than the fully bonded strip with no end-anchorage.

To find a method for improving ductility, Choi et al. (2008) conducted an investigation on the flexural behavior of partially bonded FRP strengthened concrete beams. Also, to predict the behavior of the beams, an analytical model was developed based on the curvature approach. The result of the analysis showed that ductility of the partially bonded system was improved while sustaining high load carrying capacity in comparison to the fully bonded system.

Choi et al. (2011) further investigated a partially bonded strengthening approach for RC beams utilizing NSM CFRP bars with the specific objective of improving deformability. Test results of beams with NSM CFRP bars of various unbounded lengths showed a decrease of the stiffness at the post-yield stage of the load-deflection response in the partially bonded beams. This is caused by the delayed increase of the FRP strain within the de-bonded length. As a result, the beam deformability was increased as the unbounded length increased at the same applied load. Internal slip of the FRP bar and gradual concrete failure were observed near the ultimate state, which caused a complicate nonlinear behavior of the beams. An analytical model was proposed to address the complete beam behavior including the effect of slip of FRP reinforcement and gradual concrete crushing.

From the research results of Choi et al. (2008, 2011), the deformability of RC beam retrofitted by NSM FRP strip can be improved by putting de-bonded region in the middle area of member. However, the experimental result is not enough to explain the overall behavior of $\mathrm{RC}$ beam strengthened by NSM FRP strip.

In this manner, this study carried out a flexural experiment of RC beams strengthened by EBR and NSMR with CFRP strip based on the existing results of bond tests by Seo et al. (2013). Especially, for the case of that strip is partially debonded in a region of central part to improve the deformability of FRP, the effect of de-bonded length is studied. Also, in order to improve the bond strength in the bonded region with keeping same sectional area to avoid the bond failure that may occur at where de-bonded length increases, the retrofit by using triple lines strip (the thickness of each strip is $1 / 3$ of the single strip) is planned and the retrofit effect is compared to that of single strip.

\section{Experiment}

The parameters in this experiment are a retrofit method using FRP strip and de-bonded length. The retrofit methods are NSMR and EBR, as shown in Fig. 1. NSMR is targeted at the method of making a deep and narrow groove in the surface of a member and inserting a FRP plate in it with epoxy. In order to check the improvement of strength or 

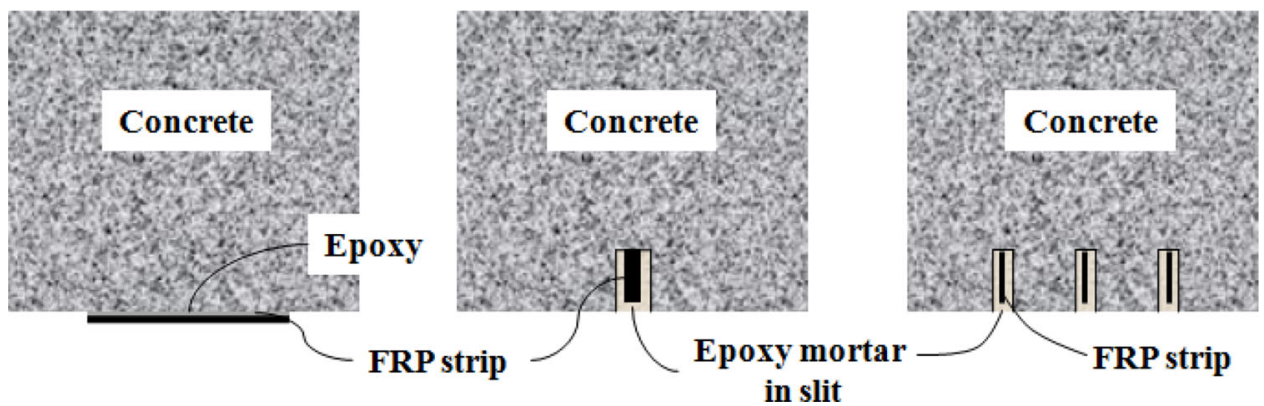

Fig. 1 Retrofit method by using FRP strip.

Table 1 Specimen list.

\begin{tabular}{|c|c|c|c|c|}
\hline Specimen names & Retrofit methods & Bonded length $(\mathrm{mm})$ & De-bonded length (mm) & $\begin{array}{c}\text { Strip dimension } \\
(\text { width } \times \text { height }) \\
(\mathrm{mm} \times \mathrm{mm})\end{array}$ \\
\hline $\mathrm{BC} 2000$ & None & - & - & \\
\hline BP1600 & EBR & 1600 & - & $50 \times 1.2$ \\
\hline CP1600-1 & \multirow[t]{8}{*}{ NSMR } & \multirow[t]{2}{*}{1600} & \multirow[t]{2}{*}{-} & $3.6 \times 16$ \\
\hline CP1600-3 & & & & $1.2 \times 16$ \\
\hline CP500-1 & & \multirow[t]{2}{*}{500 at each ends } & \multirow[t]{2}{*}{600} & $3.6 \times 16$ \\
\hline CP500-3 & & & & $1.2 \times 16$ \\
\hline CP400-1 & & \multirow[t]{2}{*}{400 at each ends } & \multirow[t]{2}{*}{800} & $3.6 \times 16$ \\
\hline CP400-3 & & & & $1.2 \times 16$ \\
\hline CP300-1 & & \multirow[t]{2}{*}{300 at each ends } & \multirow[t]{2}{*}{1000} & $3.6 \times 16$ \\
\hline CP300-3 & & & & $1.2 \times 16$ \\
\hline
\end{tabular}

deformation capacity when the bonded surface area only increased without changing the FRP area, two cases of FRP line were planned: an installation in a line for beam section; a distributed installation in triple line. The sectional areas of FRP in these two cases are almost the same.

\subsection{Specimen Design and Manufacture}

Table 1 shows the list of specimens. Figure 2 shows specimen shape and detail. After manufacturing a RC beam with the dimensions of $200 \mathrm{~mm} \times 400 \mathrm{~mm} \times 1800 \mathrm{~mm}$, flexural retrofit was performed at the bottom of the beam using a FRP strip, according to the purpose of experiment.

FRP used in experiment is composed of carbon fiber, with the thickness $1.2 \mathrm{~mm}$ and width $50 \mathrm{~mm}$. One unit of FRP was bonded for EB retrofitting. In NSMR using triple line, a FRP strip with the width $50 \mathrm{~mm}$ was divided by the width $16 \mathrm{~mm}$ into three FRP strips with the dimensions of $1.2 \mathrm{~mm} \times 16 \mathrm{~mm}$ to be used. In NSMR using one line, three $1.2 \mathrm{~mm} \times 16 \mathrm{~mm}$ strips were overlapped and bonded with epoxy into a $3.6 \mathrm{~mm}$-thick FRP bar to be used. Accordingly, the area of FRP in a specimen is almost similar to each other in all the specimens.

The 28-day compressive strength of concrete used for the specimens is $21 \mathrm{MPa}$, and FRP strip is $1.2 \mathrm{~mm}$-thick
Carbodur-Plate S512/80 made by Sika. The FRP strip has $2800 \mathrm{MPa}$ tensile strength and 160,000 MPa elastic module. According to the data presented by Sika, adhesive resin is Sikadur $^{\circledR}-30$ two-component resin, which has $70 \mathrm{MPa}$ compressive strength, $28 \mathrm{MPa}$ tensile strength, $18 \mathrm{MPa}$ shear strength, and 128,000 MPa elastic module. The yield and ultimate strength of D10 steel bar used as main bar are 486.7 and 833.2 $\mathrm{MPa}$, respectively.

\subsection{Experimental Method}

As shown in Fig. 3, specimens were installed to keep both ends in simple support condition and gradually increasing load was applied to the central part. Their failures were observed until the specimen reaches final failure. In order to measure the deformation of specimens, deflection was measured at the center of the bottom and at the $1 / 4$ point of the specimen length. In order to measure the deformations of the steel bars at the bottom and FRP, strain gauges were bonded as shown in Fig. 4. In the specimens with de-bonded region, a gauge was bonded at the center since strain is uniform in the de-bonded region. In the bonded region, also, a gauge was bonded at the point of $50 \mathrm{~mm}$ to the middle from a support and at the point of any multiple of $100 \mathrm{~mm}$ away from that point. 


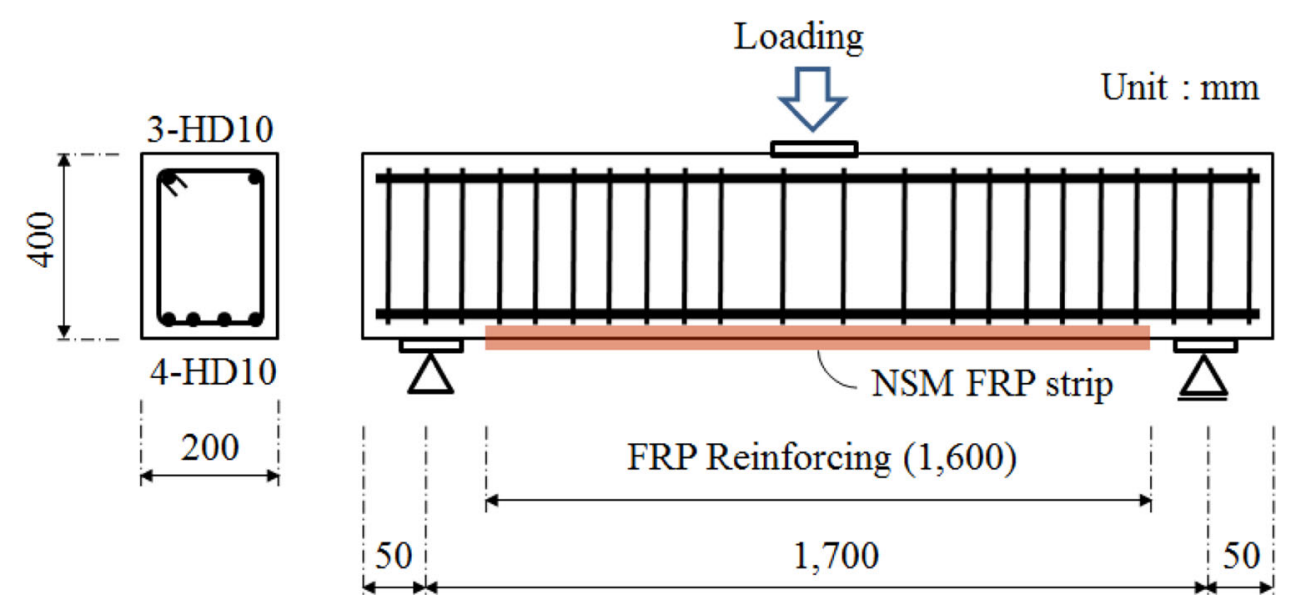

Fig. 2 Dimension and reinforcements detail.

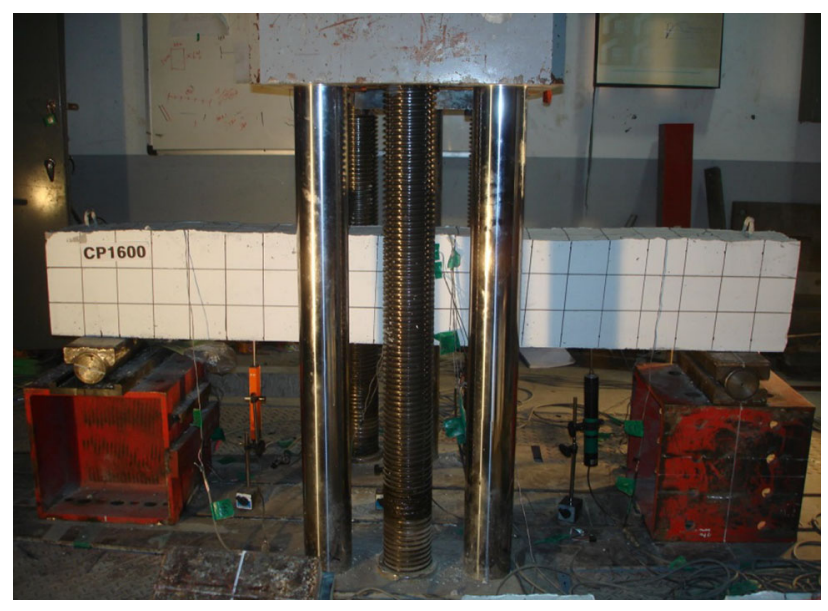

Fig. 3 Test set up.

\subsection{Test Result and Analysis \\ 3.3.1 Failure Shape}

The failure conditions of each specimen are shown in Figs. 5 and 6. As BC2000 specimen, which was not retrofitted, developed typical flexural cracks with occurrence of initial flexural crack, the central part was plasticized and the specimen reached final failure.

In the case of BP1600 specimen retrofitted using the external bonding for the retrofit region of $1600 \mathrm{~mm}$, with incremental load, flexural cracks began at a central part and relatively concentrated on the central part, compared with non-retrofitted BC2000 specimen. Finally, a failure that FRP peeled off happened.
In contrast, CP1600-1 and CP1600-3 specimens that had the whole region retrofitted by NSMR showed slightly distributed cracks without a failure that cracks appeared concentrated on a central part like BP1600 specimen. Around ultimate load, mounted FRPs fell off the central part of a beam, together with a part of cover concrete at the bottom. Especially, according to figure of the bottom of tension side in Figs. 6c and 6e, the falling-off area of CP1600-3 specimen retrofitted using the embedding in triple line was larger, compared with CP1600-1 specimen retrofitted using the embedding in a line, where a central part was de-bonded, cracks developed at regular intervals, showed an aspect that they were distributed in the whole de-bonded region, and concrete did not fall off. FRP ruptured in all the de-bonded regions. Afterward, it showed a failure almost similar to that of non-retrofit specimen.

Further, it can be found that both CP1600-1 specimen using NSMR and BP1600 specimen retrofitted using EBR for the whole bottom had cracks concentrated on a central part and that, accordingly, concrete fell off. In contrast, a non-retrofit specimen and a specimen using partial de-bonding for a central part had flexural cracks distributed wholly, and accordingly, there was no seriously concentrated falling off area. Thus, a failure can be distributed without being concentrated on a central part by de-bonding for the central part.

\subsubsection{Load-Deflection Curve}

Figure 7 shows each comparative load-deflection curve based on the bonded length for a specimen using NSMR and

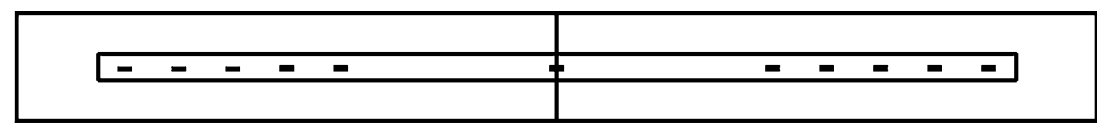

(a) Bottom side

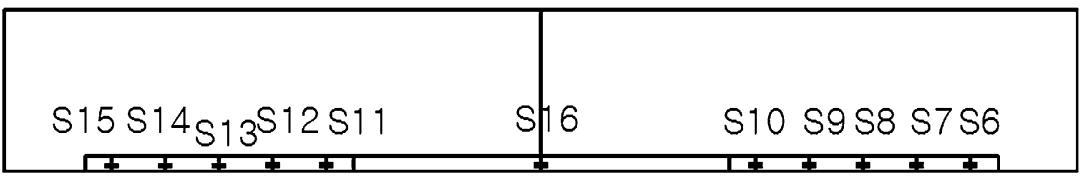

(b) Front side

Fig. 4 Locations of strain gauges on FRP. 
Table 2 Test and calculated results.

\begin{tabular}{|c|c|c|c|c|c|c|c|c|c|c|}
\hline \multirow[t]{2}{*}{ Specimens } & \multirow[t]{2}{*}{$P_{c r}(\mathrm{kN})$} & \multicolumn{2}{|c|}{ Yield } & \multicolumn{2}{|c|}{ Ultimate } & \multirow[t]{2}{*}{$\mu\left(\delta_{u} / \delta_{y}\right)$} & \multirow[t]{2}{*}{$\Delta P(\mathrm{kN})$} & \multirow[t]{2}{*}{$P_{n}(\mathrm{kN})$} & \multirow[t]{2}{*}{$\frac{P_{u}}{P_{n}}$} & \multirow{2}{*}{$\begin{array}{l}\text { Failure } \\
\text { patterns }\end{array}$} \\
\hline & & $P_{y}(\mathrm{kN})$ & $\delta_{y}(\mathrm{~mm})$ & $P_{u}(\mathrm{kN})$ & $\delta_{u}(\mathrm{~mm})$ & & & & & \\
\hline BC2000 & 42.65 & 143.18 & 6.03 & 190.24 & 79.61 & 13.20 & - & 109.65 & 1.73 & $\begin{array}{r}\text { Ductile } \\
\text { failure }\end{array}$ \\
\hline BP1600 & 56.93 & 167.20 & 5.97 & 190.25 & 10.12 & 1.70 & 45.6 & 186.97 & 1.02 & FRP peel off \\
\hline CP1600-1 & 66.20 & 200.55 & 6.72 & 225.55 & 15.98 & 2.38 & 72.08 & 206.32 & 1.09 & FRP fracture \\
\hline CP1600-3 & 46.58 & 173.58 & 6.63 & 233.40 & 26.13 & 3.94 & 72.08 & 206.32 & 1.13 & \\
\hline CP500-1 & 42.17 & 161.32 & 6.35 & 208.39 & 19.06 & 3.00 & 54.92 & 193.10 & 1.08 & \\
\hline CP500-3 & 53.45 & 162.79 & 6.04 & 233.40 & 26.13 & 4.33 & 72.08 & 206.32 & 1.13 & \\
\hline $\mathrm{CP} 400-1^{\mathrm{a}}$ & 52.50 & 163.50 & - & 225.00 & - & - & - & 185.81 & 1.21 & \\
\hline CP400-3 & 41.19 & 151.02 & 6.60 & 224.08 & 29.67 & 4.50 & 59.82 & 206.32 & 1.09 & \\
\hline CP300-1 & 40.21 & 154.95 & 6.63 & 194.17 & 19.16 & 2.89 & 40.7 & 177.23 & 1.10 & \\
\hline CP300-3 & 53.94 & 145.14 & 6.70 & 212.31 & 24.46 & 3.65 & 52.95 & 203.93 & 1.04 & \\
\hline
\end{tabular}

$P_{c r}$ is cracking load, $P_{y}$ and $\delta_{y}$ are load and displacement at yield state, $P_{u}$ and $\delta_{u}$ are load and displacement at ultimate state, $\Delta P$ is load increase by FRP retrofit and $P_{n}$ is calculated load through the calculation process of flexural strength by Eq. (1).

${ }^{a}$ Displacement data of this specimen were not recorded.

Table 3 Internal tensile forces of NSM FRP strip.

\begin{tabular}{c|r|r|r|r|r|r}
\hline \multirow{2}{*}{$\begin{array}{c}\text { Resisting } \\
\text { force }\end{array}$} & \multicolumn{3}{|c|}{ single line } & \multicolumn{3}{c}{ Total of triple lines } \\
\cline { 2 - 7 } & \multicolumn{1}{|c|}{400} & \multicolumn{1}{|c|}{500} & 300 & \multicolumn{1}{c}{400} & \multicolumn{1}{c}{500} \\
\hline \hline$T_{f 1}(\mathrm{kN})$ & 161.28 & 161.28 & 161.28 & 161.28 & 161.28 & $\mathbf{1 6 1 . 2 8}$ \\
\hline$T_{f 2}(\mathrm{kN})$ & 172.80 & 230.40 & 288.00 & 518.40 & 691.20 & 864.00 \\
\hline$T_{f 3}(\mathrm{kN})$ & $\mathbf{1 2 2 . 0 5}$ & $\mathbf{1 3 4 . 0 1}$ & $\mathbf{1 4 4 . 0 9}$ & $\mathbf{1 5 7 . 6 0}$ & $\mathbf{1 6 0 . 6 9}$ & 164.05 \\
\hline$T_{f}(\mathrm{kN})$ & 122.05 & 134.01 & 144.09 & 157.60 & 160.69 & 161.28 \\
\hline$T_{f} / T_{f 1}$ & 0.76 & 0.83 & 0.89 & 0.98 & 1.00 & 1.00 \\
\hline
\end{tabular}

Bold one represents the minimum value governing the failure

a specimen using EBR. CP400-1 specimen was omitted from the graph as its data was not stored due to errors in the experiment. According to Fig. 7, in spite of the same retrofit amount, the specimen strengthened by NSMR has greater strength, compared with the specimen by EBR. Besides, the arrival time of ultimate load of a member is more delayed for the former than the latter. This is because of that FRP is mounted in a slit and its bond strength is increased by the confining effect of concrete around the slit.

In NSMR, as the de-bonded length of a specimen is longer, the ultimate strength gets lower and the stiffness becomes lower up to the ultimate load after yield. The reason is that, as de-bonded region is longer, the deformation of a FRP increases uniformly in de-bonded region, and accordingly deformation gets greater.

When bonded length is the same-proportioned, NSMR using triple line showed greater ultimate strength and deflection compared with NSMR using a line. The reason is that where FRP strip is distributed in triple line despite the same bonded length, the anchorage capacity of FRP in bonded region is improved as a bonded area gets comparatively larger.

Although the de-bonded length in a central part of CP500-3 specimen is $600 \mathrm{~mm}$, the load-deflection curve up to ultimate load of the specimen is nearly identical to that of CP1600-3 specimen using complete bonding for the total length. This means that if bonded length secures $500 \mathrm{~mm}$ at both ends, a specimen using partial de-bonding for a central part has the same capacity as a specimen retrofitted using complete bonding. In the comparison of the fully bonded NSMR specimens, CP1600-3 with triple lines has higher ultimate strength than CP1600-1 with single line. But on the other hand CP1600-1 showed linear stiffness until $200 \mathrm{kN}$ which is higher than that of CP1600-3(170 kN). It is thought that the reason is that the three lines of strips reached their elastic limit at different time, respectively so that the elastic limit of the RC beam strengthened by triple lines of thin FRP strips reduced while the inelastic deformation capacity increased. From this, a special consideration is necessary when a beam is strengthened with full bonding NSMR by using too thin FRP strip.

The initial crack of all specimens occurred at the bottom of the beams below loading point. It is known that the cracking load closely depends on the concrete strength and will be increased when its initial stiffness increases. All specimens have same concrete strength and their initial stiffness is almost same regardless of FRP strengthening (from Fig. 7). This means that the FRP strengthening the bottom of RC beam does not contribute the increase of initial stiffness.

\subsubsection{Load-Strain Curve}

As the result of an observation of a change in the value of strain gauges bonded at regular intervals, as shown in Fig. 4, aimed to find the strain distribution of FRP as load acts, strain was high in a central part that a lot of cracks happen on 


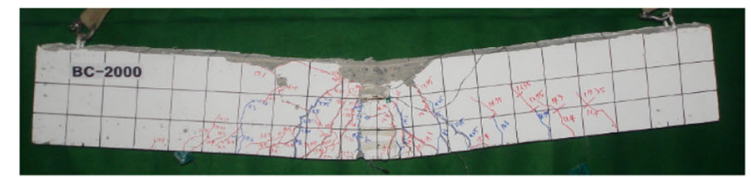

(a) $\mathrm{BC} 2000$

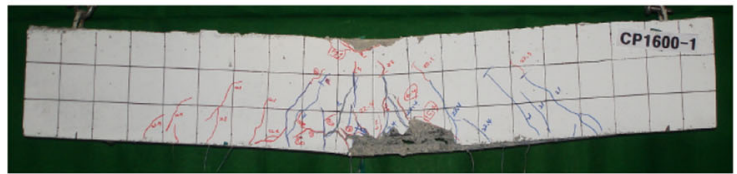

(c) CP1600-1

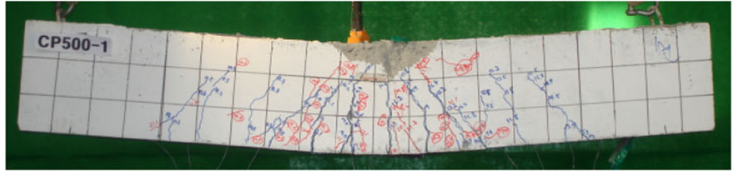

(e) CP500-1

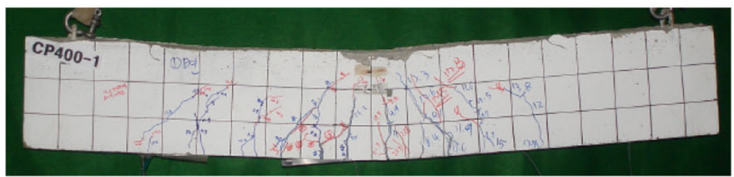

(g) $\mathrm{CP} 400-1$

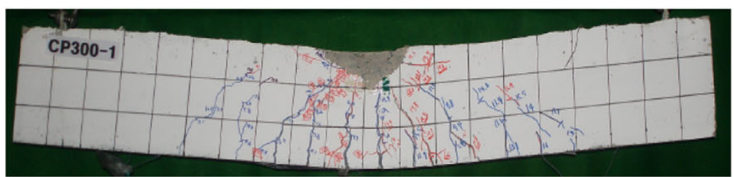

(i) $\mathrm{CP} 300-1$

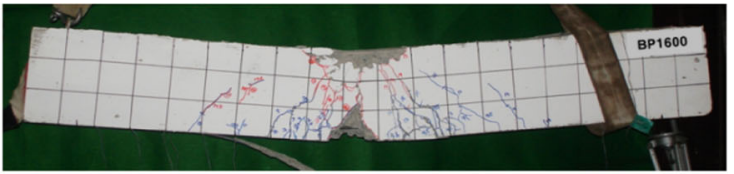

(b) BP1600

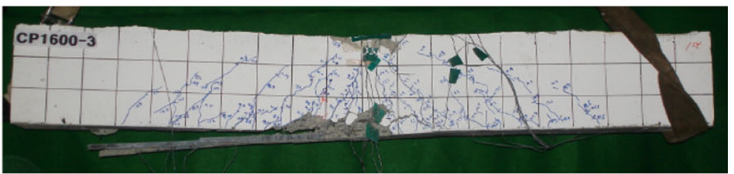

(d) $\mathrm{CP} 1600-3$

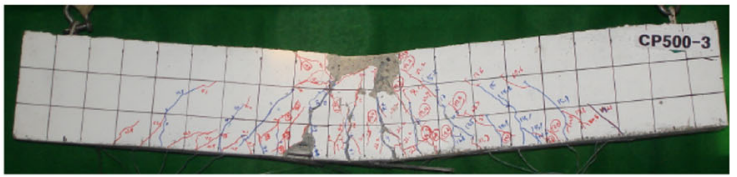

(f) CP500-3

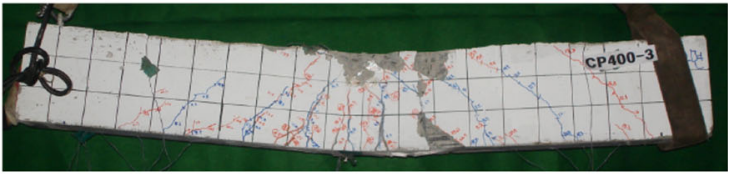

(h) $\mathrm{CP} 400-3$

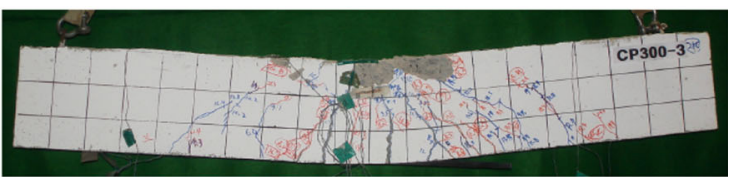

(j) $\mathrm{CP} 300-3$

Fig. 5 Failure shape of specimens.

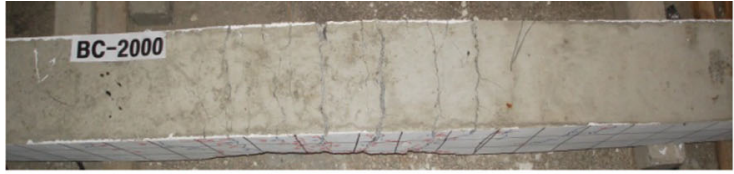

(a) BC-200

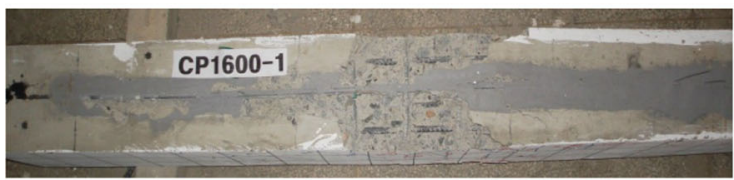

(c) $\mathrm{CP} 1600-1$

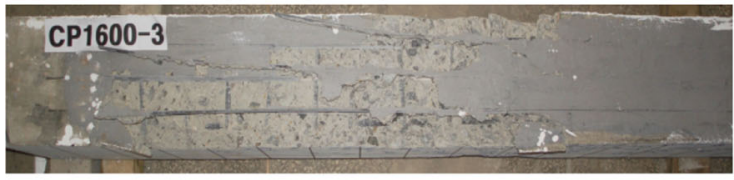

(e) CP1600-3

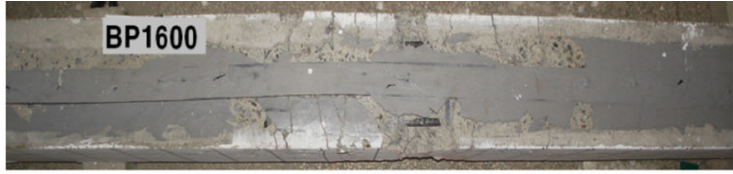

(b) BP1600

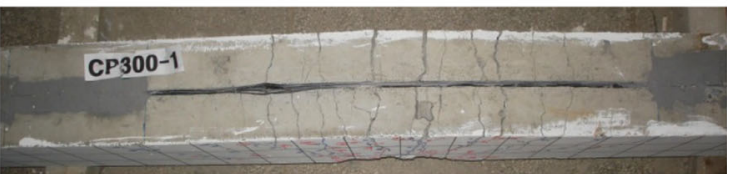

(d) CP300-1

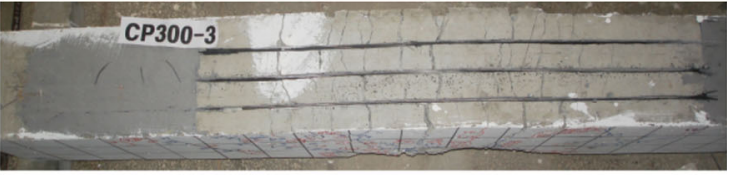

(f) $\mathrm{CP} 300-3$

Fig. 6 Crack pattern of bottom surface failed in tension.

the whole. In order to compare strain distributions by experimental variables, Fig. 8 shows the comparison of strains at the time that the deflection of a member is $L / 250$.
All FRP strains are deemed the same in de-bonded region, therefore the strain values in the de-bonded region are shown to be uniform. 


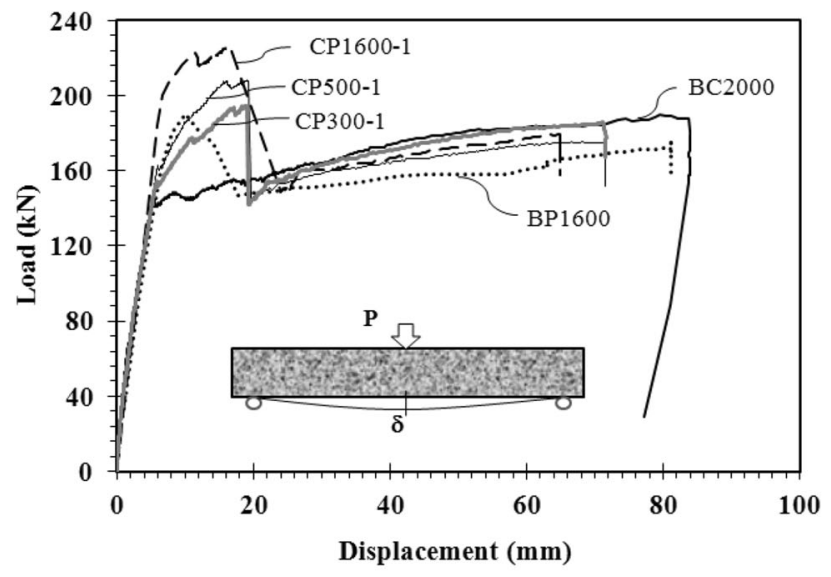

(a) Specimens with single line strip

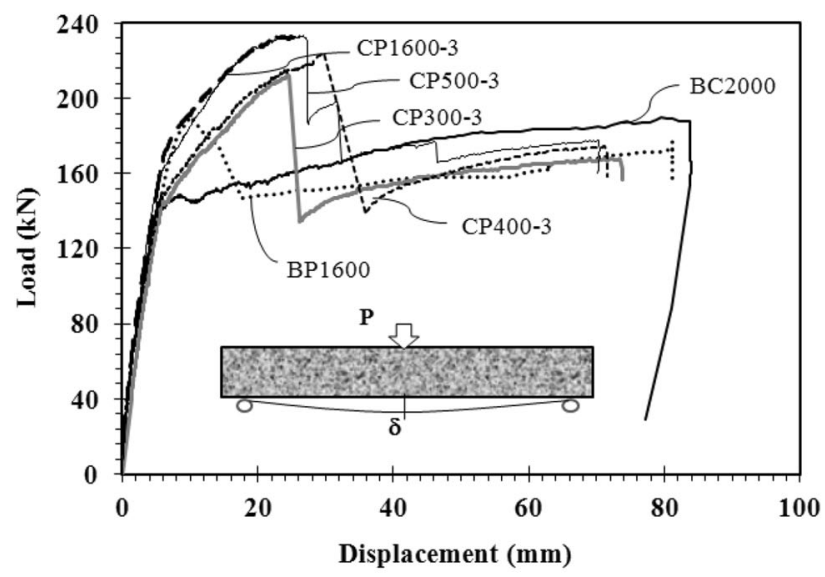

(b) Specimens with triple lines strip

Fig. 7 Load-deflection curves of specimens.

The strain of FRP strip used for NSMR was higher than that of FRP strip used for EBR, and the retrofit using triple line showed a higher strain distribution than that using a line. In the case of NSMR using a line, CP1600-1 specimen without de-bonding showed the strain values which is very similar to CP300-1 whose de-bonded length in a central part is $1000 \mathrm{~mm}$. Although BP1600 and CP1600-1 specimens were expected to show high strain in a central part, their strain distributions are uniformly formed in a certain region of a central part. The data of a strain gauge bonded to a central part was not measured for CP500-1 specimen due to the gage problem.

As shown in Fig. 8b, a specimen using NSRM in triple line showed higher strain distribution under $L / 212$ at the same deflection as described above, compared with a specimen using NSMR in a line. Especially, CP1600-3 specimen using triple line embedding for the total length showed remarkably high FRP strain in a central part, unlike CP16001 specimen using a line embedding. This means that deformation is concentrated on a central part of FRP. The ultimate strain value of CP500-3 specimen, whose de-bonded central part is $600 \mathrm{~mm}$ in length, is similar to that of
CP1600-3 specimen. Actual load-deflection curve in Fig. 7b shows that the behaviors of two specimens up to ultimate load are nearly identical to each other. This means that where anchorage capacity at end of FRP is sufficiently secured, the effect of complete bonding for the whole region can be gained even though some of a central part is de-bonded. As the de-bonded length of a central part is longer, the value of ultimate strain of FRP decreases, which means that the strength exerted by tensile side decreases.

\subsubsection{Comparison of Test Results}

Figure 9 indicates loads of all specimens at initial cracking, yield and ultimate. Also, the displacements at each critical load are summarized in Table 2. The specimens retrofitted with EB FRP or NSM FRP bonded along the entire length of the members showed similar cracking loads with the specimens retrofitted with partially de-bonded FRP for a central part. As mentioned previously, all specimens have same concrete strength and their initial stiffness is almost same regardless of CFRP strengthening. This means that the CFRP strengthening the bottom of RC beam does not contribute the increase of initial stiffness.

All specimens showed higher yield load than non-retrofitted specimen. The specimen that showed highest yield strength was CP1600-1 specimen, followed by BP1600 specimen. A specimen using partially de-bonded FRP for a central part as NSMR, except CP300 series, showed an increase in displacement after yield with an increase in debonded length, as described in the load-displacement curve. In the case of completely bonded FRP for the total length, deformation was concentrated on FRP in a cracked area. In contrast, deformation happens uniformly to FRP in debonded region with an increase in the de-bonded length of a central part, which, supposedly, increased the amount of deformation on the whole.

The strength increase by retrofit was calculated to evaluate the retrofit effect by each specimen. As shown in Fig. 10, the strength increase was deemed as the strength difference between the values of non-retrofit specimen and retrofitted specimen for the same displacement at the occurrence of ultimate strength increased after yield.

Figure 11 shows the degree of strength increase by each specimen. In the case of a specimen using NSMR, as debonded length is shorter (bonded length is longer), strength increase by retrofit is larger. Compared with BP1600 specimen retrofitted using external bonding, the strengths of all specimens, except CP300-1 the bonded length of whose ends is $300 \mathrm{~mm}$ and which is retrofitted using the embedding in a line, is higher than that of a specimen retrofitted using external bonding.

In particular, CP300-3, whose bonded area was comparatively increased by embedding in triple line despite of a short bonded length of $300 \mathrm{~mm}$, showed a bond failure, but its strength was higher than that of EBR. Although CP500-3 


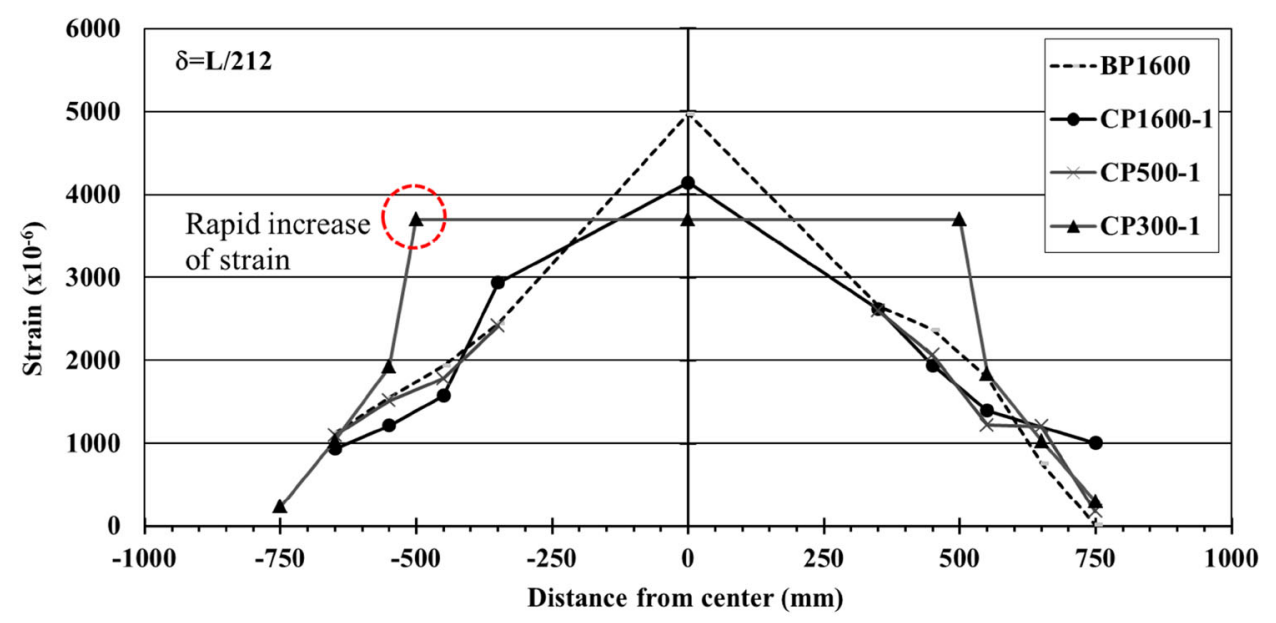

(a) Specimens with single line strip

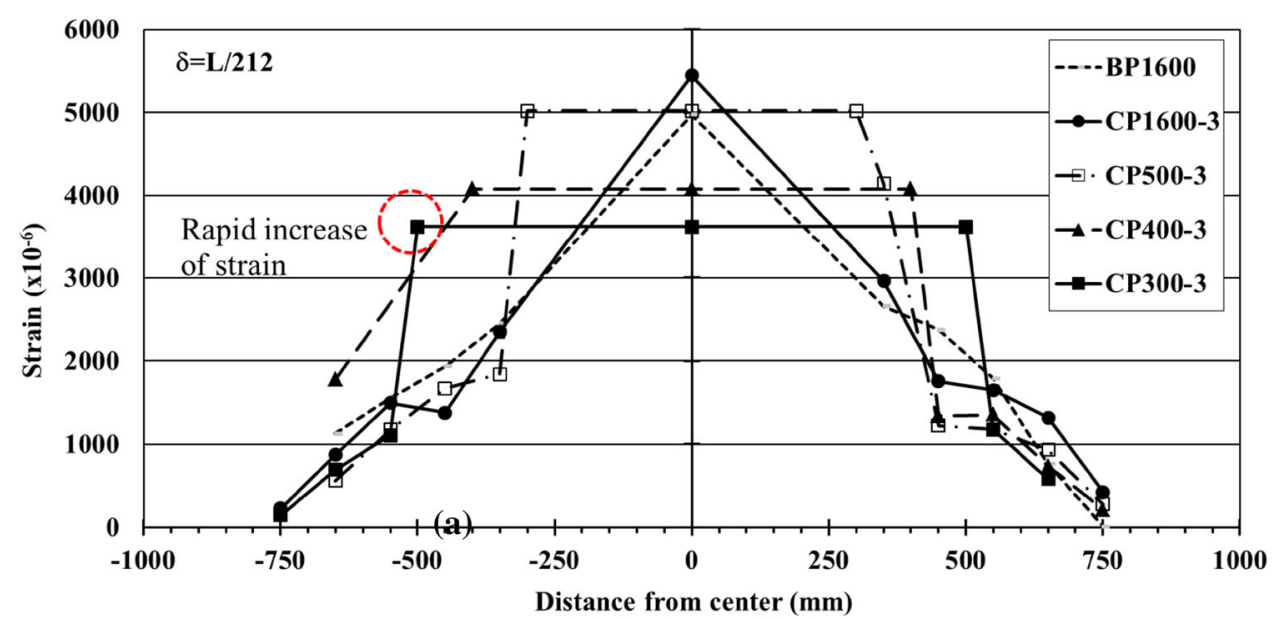

(b) Specimens with triple lines strip

Fig. 8 Comparison of FRP strains at $\delta=L / 212$.

specimen had a de-bonded length of $600 \mathrm{~mm}$, it showed the same strength as CP1600-3 specimen with fully bonded FRP for whole length. This means that, where sufficient length is secured at ends, strength decrease arising from de-bonding will never happen.

Figure 12 shows ductility ratio which is the ratio of displacement at ultimate strength and displacement at yield. According to this figure, in the case of all specimens except CP300 series specimens, ductility ratio increases with an increase in de-bonded length. CP300 specimen has very short bond length at both sides while it has relatively long de-bonded region in central part. In this case, the strain in the bonded region tends to rapidly increase from the support to the starting point of de-bonded region; there is a rapid increase of FRP strain along with the bonded length from the strain distribution of FRP in Fig. 8. If the bonded length is enough to resist the tension force acting to the FRP, the behavior of FRP in de-bonded region governs and shows relatively ductile behavior. However, if not, the bond failure in the bonded region governs overall behavior of the beam showing brittle behavior. The bond length of CP300 specimen is not enough to show ductile behavior. Where anchorage length is sufficiently secured, strength decrease will not happen, and deformation capacity can be improved even though de-bonded length is increased.

\section{Flexural Strength in Retrofit Using FRP Strip}

Where FRP strip is bonded externally or mounted near surface for retrofit, the relation between strain and flexural stress according to ACI 440-2R (2002) is shown in Fig. 13 and flexural strength can be calculated as follows:

$$
\begin{aligned}
M_{n}= & A_{s}^{\prime} f_{y}\left(d-d_{1}\right)+\left(A_{s}-A_{s}^{\prime}\right) f_{s}\left(d-\frac{\beta_{1} c}{2}\right) \\
& +k_{m} A_{f} f_{f}\left(d_{f}-\frac{\beta_{1} c}{2}\right)
\end{aligned}
$$

where $A_{s}$ and $A_{s}^{\prime}$ are sectional areas of tensile and compression bar, respectively, $\beta_{1}$ is ratio of depth of rectangular stress block, $c$ is distance from extreme-compression fiber to neutral axis, $d$ and $d_{1}$ are effective depth and distance from extreme-compression fiber to centroid of compression reinforcement, respectively, $A_{f}$ is sectional area of FRP 


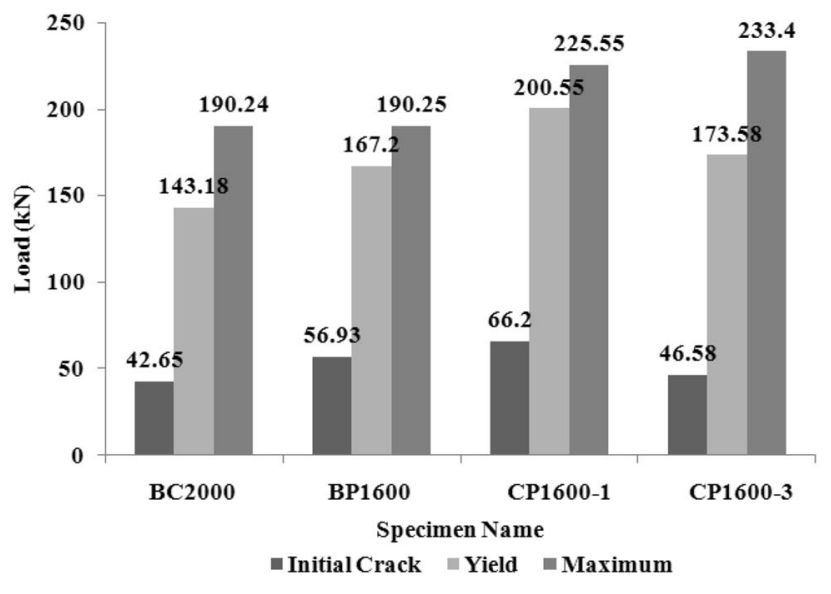

(a) In the case of different retrofit method

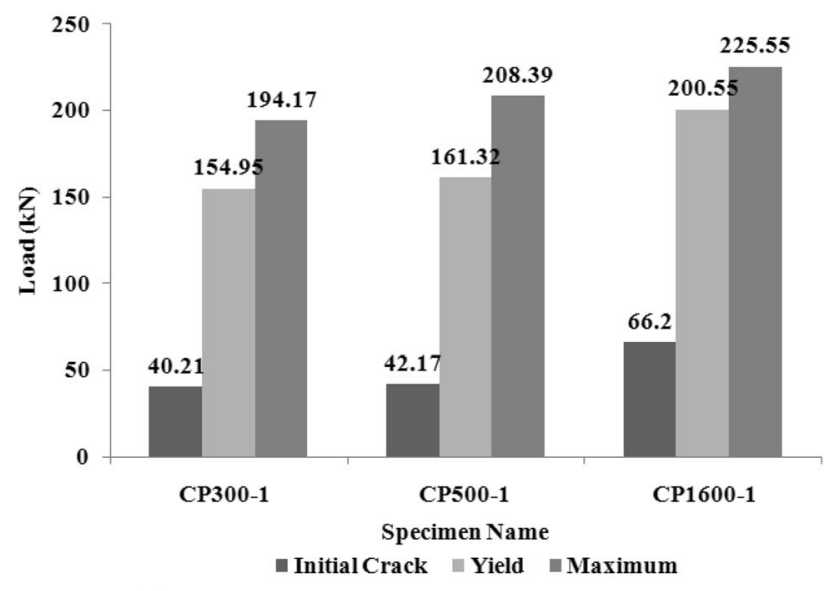

(b) In the case of different bond length in single line strip

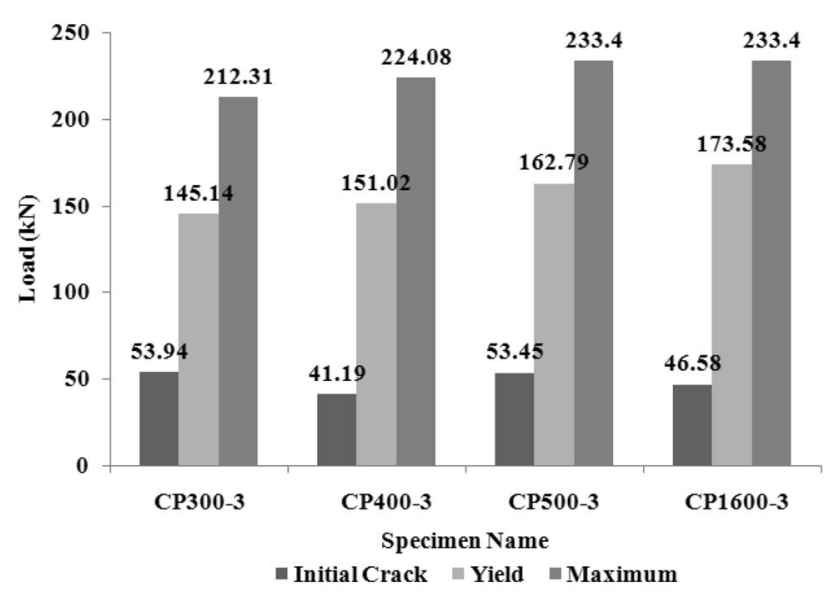

(c) In the case of different bond length in triple lines strip

Fig. 9 Strength comparison of specimens at initial crack, yield and ultimate.

reinforcement, $f_{y}$ is yield strength of bar, $f_{s}$ and $f_{f}$ are stress in bar and FRP reinforcement, respectively, $k_{m}$ is reduction factor considering the bond loss between FRP and concrete and $d_{f}$ is distance from extreme-compression fiber to centroid of FRP reinforcement.

Strain of FRP and reinforcement can be calculated using the following formula (2002).

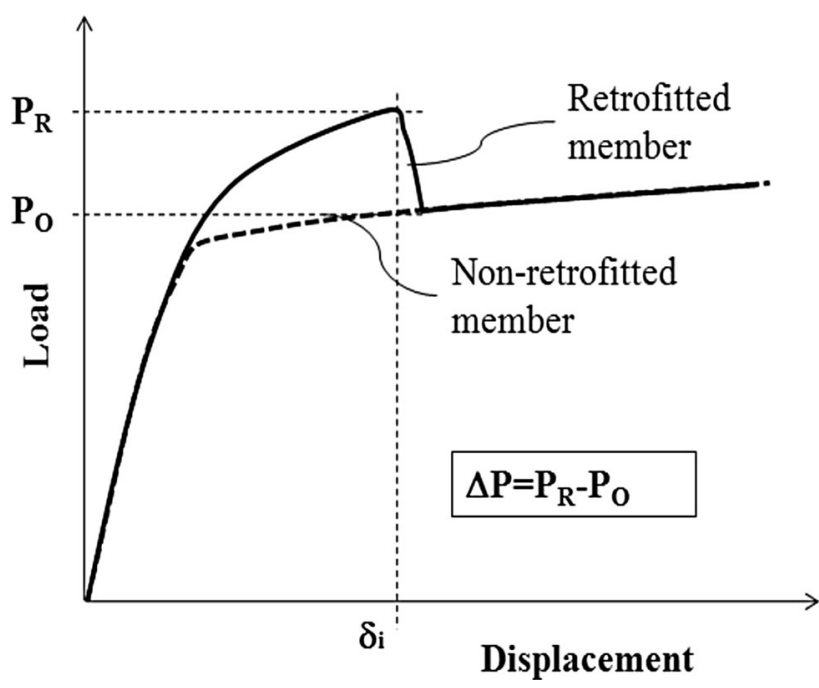

Fig. 10 Definition of strength increase by retrofit.

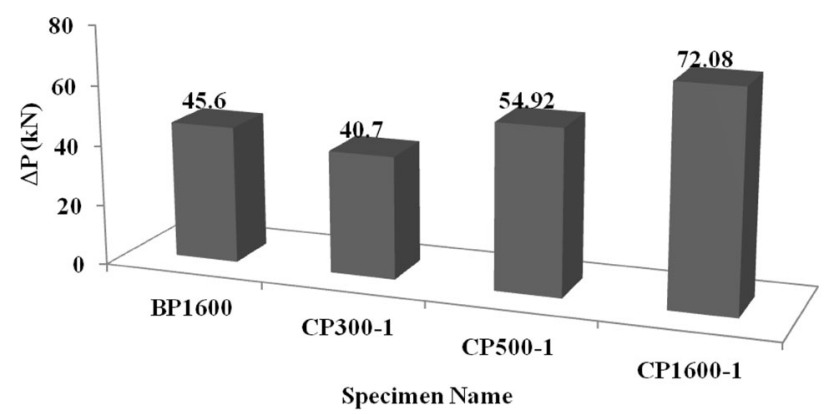

(a) EBR specimen and NSMR specimens with single line strip

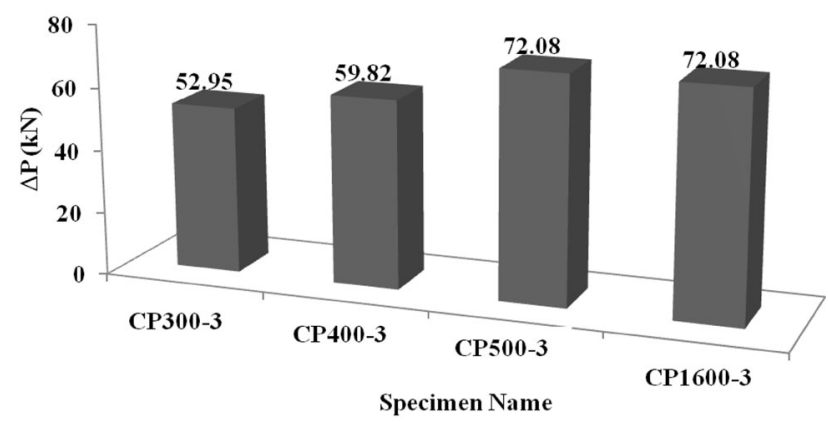

(b) NSMR specimens with triple lines strip

Fig. 11 Strength increases of specimens by retrofit.

$$
\begin{aligned}
& \varepsilon_{f e}=0.003\left(\frac{d_{f}-c}{c}\right) \leq k_{m} \varepsilon_{f u} \\
& \varepsilon_{s}=\varepsilon_{f e}\left(\frac{d-c}{d_{f}-c}\right) \\
& c=\frac{\left(A_{s}-A_{s}^{\prime}\right) f_{s}+A_{f} f_{f e}}{\gamma f_{c k} \beta_{1} b}
\end{aligned}
$$

where $\varepsilon_{f e}$ and $\varepsilon_{f u}$ are effective strain and ultimate strain of FRP reinforcement, respectively, and $\varepsilon_{s}$ is strain of tensile bar. 


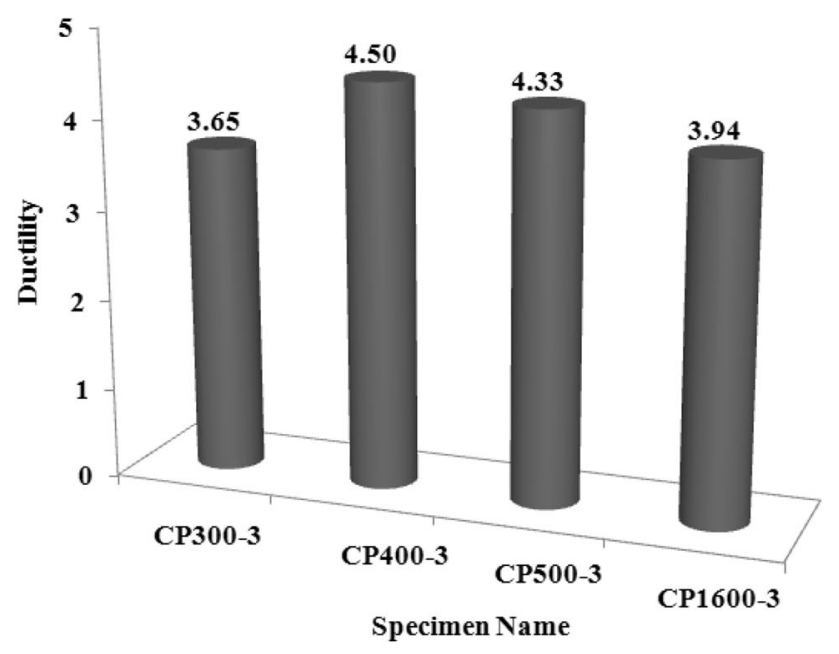

(a) NSMR specimens with single line strip

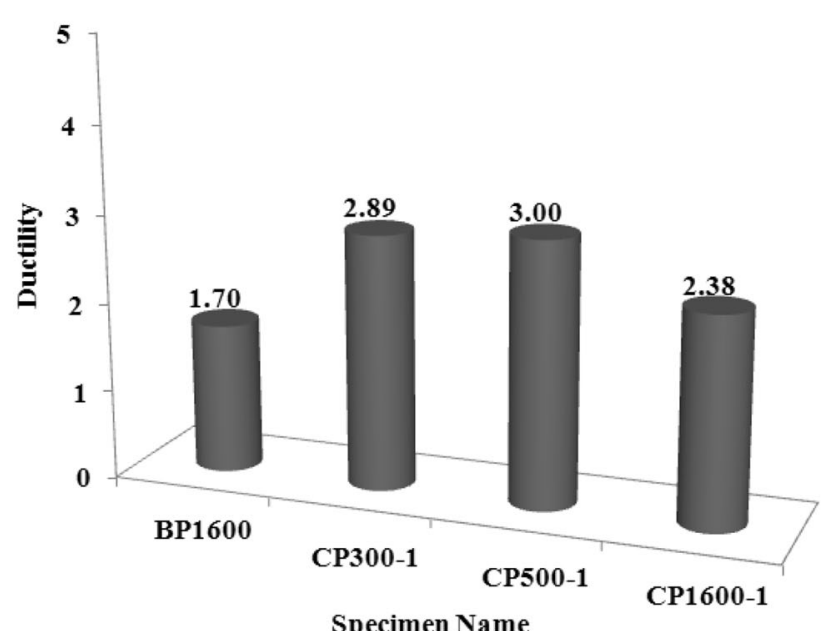

(b) NSMR specimens with triple lines strip

Fig. 12 Ductility of NSMR specimens.

In EBR, $k_{m}$ is a reduction coefficient considering peeling off of FRP before reaching the ultimate stress and can be calculated using Eq. (5) (2002).

$$
k_{m}=\left\{\begin{array}{cl}
\frac{1}{60 \varepsilon_{f u}}\left(1-\frac{n E_{f} t_{f}}{360,000}\right) \leq 0.9 & \text { for } n E_{f} t_{f} \leq 180,000 \\
\frac{1}{60 \varepsilon_{f u}}\left(\frac{90,000}{n E_{f} t_{f}}\right)>0.9 & \text { for } n E_{f} t_{f}>180,000
\end{array}\right.
$$

where $n$ is layer number of FRP plate, $E_{f}$ is elastic module of FRP, and $t_{f}$ is thickness of FRP reinforcement.

As a result of calculation of $k_{m}$ by Eq. (5), a bond reduction factor of a beam retrofitted using external bonding method was 0.5 , and accordingly, the strength of a retrofitted member was calculated at $126.5 \mathrm{kN}$. This value is low, compared with $190.25 \mathrm{kN}$ which is a result of actual experiment. Where 0.9, maximum value in Eq. (5), is used as bond reduction factor, the strength of a retrofitted member is calculated at $176.37 \mathrm{kN}$, which is still low compared with an experiment result. According to these findings, the method for evaluating the strength of ACI 440-2R tends to underestimate an experimental result, in evaluating the strength of a beam retrofitted with EB FRP plate.

According to the result of experiment by Seo et al. (2013), in the case of NSMR, bond reduction factor varies according to embedment length. Especially, where a partial de-bonding method is used for a central part like this study, the extent that FRP is fastened to ends changes according to the bond length of ends. Consequently, it is desirable to calculate a reduction factor considering a mechanism of fracture of anchorage.

The mechanism of fracture in the areas of anchorage at ends of NSM FRP can be classified into tensile rupture of mounted FRP strip, shear failure of infilled epoxy, and failure by falling-off of concrete. As shown in Fig. 14, the resisting force is decided by the smallest value among FRP tensile strength $T_{f 1}$, epoxy shear strength $T_{f 2}$ and force by bond strength of concrete $T_{f 3}$ (Seo et al. 2013).

$$
\begin{aligned}
& T_{f}=\min \cdot\left\{T_{f 1}, T_{f 2}, T_{f 3}\right\} \\
& T_{f 1}=\phi A_{f} f_{f} \\
& T_{f 2}=\lambda \tau_{e f}\left(2 b_{f} h_{e}\right) \\
& T_{f 3}=\alpha_{p} 0.85 n_{g} \eta \phi_{f}^{0.25} f_{c k}^{0.33} \sqrt{\left(L_{p e r} \gamma\right)(E A)_{f}}
\end{aligned}
$$

where $\lambda$ is effective bond loss factor, $\tau_{e f}$ is shear strength of epoxy, $b_{f}$ and $h_{e}$ are width and bonded length of NSM FRP strip, respectively, $\gamma=\left(h_{e} / L_{p e r}\right)^{0.65}, \quad \eta=\left(L_{p e r} \gamma+B_{e}\right) /$ $\left(n L_{p e r} \gamma\right) \leq 1.0, L_{p e r}=2 b_{f}+t_{f}, \quad \phi_{f}=b_{f} t_{f}$. And $(E A)_{f}$ is stiffness of FRP reinforcement, $n_{g}$ is number of FRP strip in considering group effect, $B_{e}$ is distance between centroids of FRP reinforcements located at extreme sides, and $\alpha_{p}$ is 1.0 as typical value and 0.85 as low bound.

Equation (6-3) suggested by Seo (2012) is a formula considering group effect arising out of a compact space between FRPs, based on empirical formula of Seracino et al. (2007). The resisting force at FRP member anchorage according to bond length, calculated based on Eq. (6), is shown in Table 3.

Where FRP strip is a line, the resisting force by bond failure, $T_{f 3}$ turns out lowest up to $500 \mathrm{~mm}$ in bond length. Where FRP strip is distributed in triple line, the tensile strength of FRP strip, $T_{f 1}$ turns out lowest from $500 \mathrm{~mm}$ in bond length. Compared with the resisting force at tensile rupture, the ratio from 0.76 to 0.89 is shown according to the bond length ranging from 300 to $500 \mathrm{~mm}$ in the case of embedding in a line. In the case of embedding in triple lined distribution, the ratio is calculated at 0.98 and 1.0 at $300 \mathrm{~mm}$ and more in bond length, respectively. Using these values as $k_{m}$ which is bond reduction factor of Eq. (2), flexural strength that reflects the effect of bond failure can be calculated. The value is indicated by $P_{n}$ shown in Table 2 . Figure 15 shows the ratio of an experiment result to a calculation result, by bond lengths. From $P_{u} / P_{n}$ values of the 


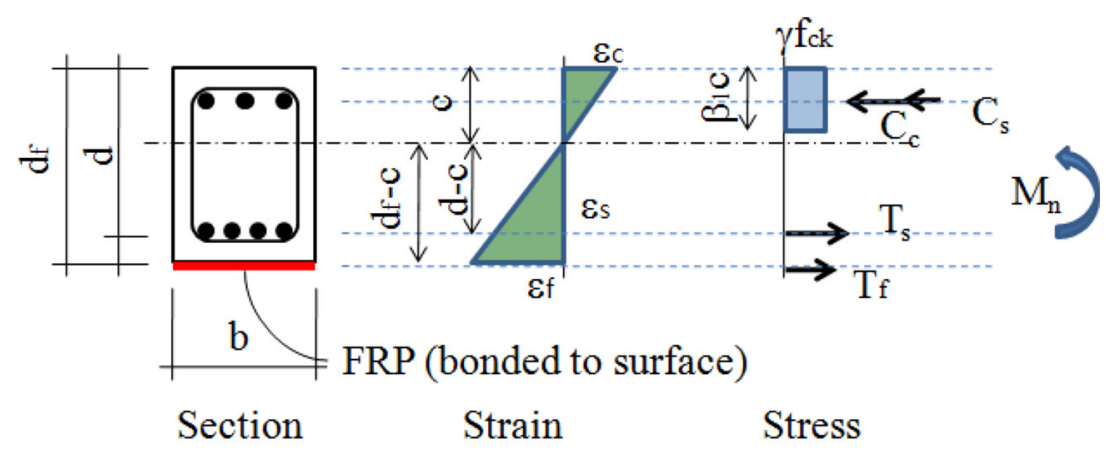

(a) EBR

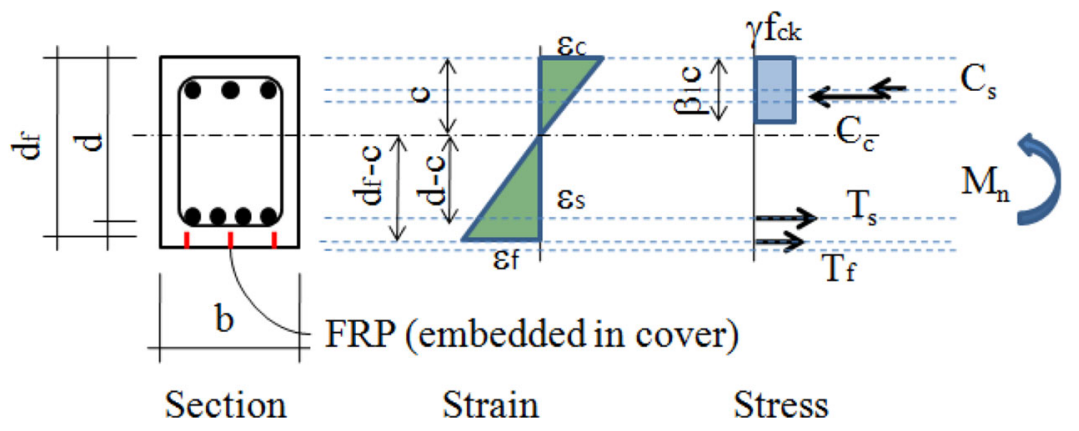

(b) NSMR

Fig. 13 Stress and strain relation of retrofitted beam according to retrofit method.

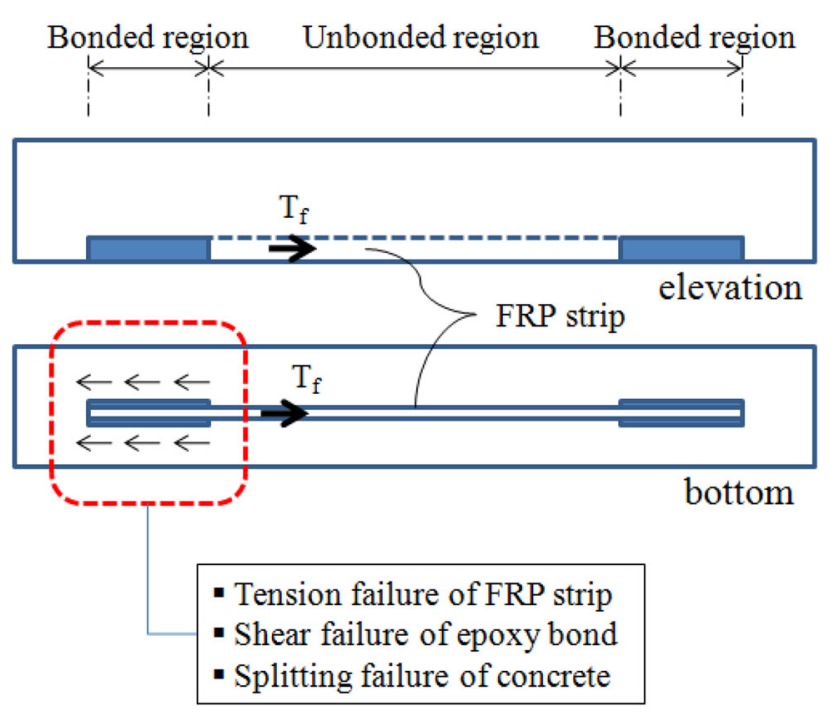

Fig. 14 Internal force of partially de-bonded FRP.

specimens strengthened by FRP, the range of deviation is acceptable not too high (maximum is $21 \%$ at CP400-1) and the flexural strength is safely predicted by using the process.

\section{Conclusions}

In this paper, an experimental work was presented to study the flexural strength of RC beams strengthened by partially de-bonded NSM FRP strip with various de-bonded length. Especially, considering high anchorage capacity at end of a NSM FRP strip, the effect of de-bonded region at a central

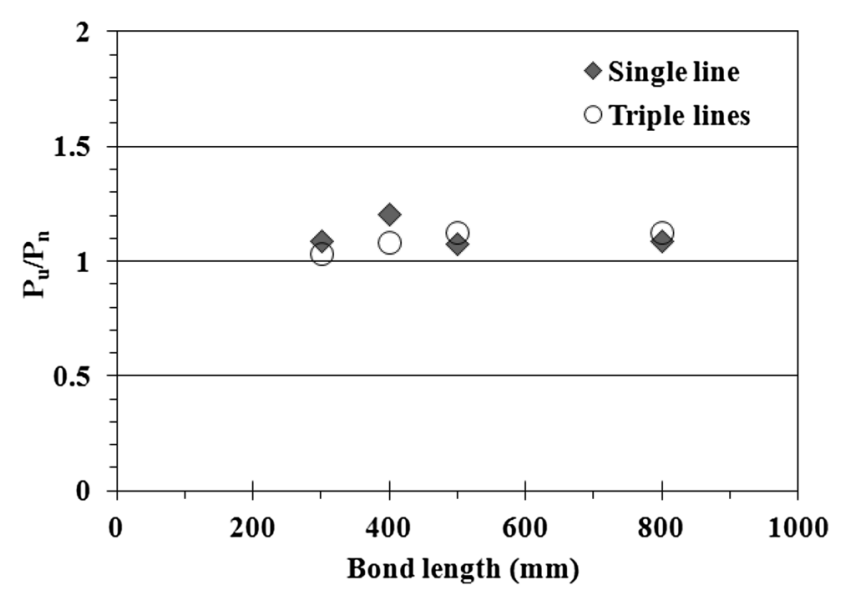

Fig. 15 Comparison of the calculated flexural strengths and test results.

part was investigated. In addition, the retrofit by using triple strips (the thickness of each strip is $1 / 3$ of the single strip) was evaluated in order to improve the bond strength in the bonded region, The flexural strength of a RC member strengthened by a partially de-bonded NSM FRP strip was evaluated by using the existing researchers' strength equation for calculation of the strength after retrofit. From the study, the following conclusions were drawn.

The retrofit of mounting FRP strip in the cover concrete of $\mathrm{RC}$ beam, as the flexural retrofit method for RC members using FRP, exerts high retrofit capacity compared with the existing EBR method. The reason is that relatively high bond capacity of FRP can be secured by mounting FRP strip vertically. 
Where NSM FRP strips are distributed in triple line, a relatively high strength can be exerted through an increase in the bond strength of anchorage. This means that where the retrofit method of mounting thin strip can fully exert tensile strength of FRP even though the bonded region is small. Accordingly, the de-bonded region of a central part can be increased. However, a special consideration is necessary when a beam is fully bonded by using NSMR with too thin FRP strip since the yield strength can be decreased.

The resisting force of a member retrofitted with NSM FRP turned out to be properly evaluated by following the method of calculating the resisting force in flexural retrofit of ACI $440-2 \mathrm{R}$ and considering three types of fracture of anchorage.

Where de-bonded region exists in the central part of a flexural member, the deformation capacity of a member is expected to be relatively improved, because FRP strain is not to be concentrated on the center but to be extended uniformly in the de-bonded region. Based on this, a design to induce ductile fracture of a member can be feasible. Consequently, it is necessary to conduct a study on the effect of the de-bonding of aramid and glass FRP other than CFRP targeted by this study. Moreover, it is also necessary to conduct an interpretative study on an evaluation of flexural displacement that reflects the deformation of a central part.

\section{Acknowledgments}

This research was supported by 2011 Basic Science Research Program through the National Research Foundation of Korea (NRF) funded by the Ministry of Education, Science and Technology (2011-0011350).

\section{Open Access}

This article is distributed under the terms of the Creative Commons Attribution 4.0 International License (http:// creativecommons.org/licenses/by/4.0/), which permits unrestricted use, distribution, and reproduction in any medium, provided you give appropriate credit to the original author(s) and the source, provide a link to the Creative Commons license, and indicate if changes were made.

\section{References}

ACI Committee 440. (2002). Guide for the design and construction of concrete reinforced with FRP bars (ACI 440.2R-02). American Concrete Institute.

Ali, M., Oehlers, D., Friffith, M., \& Seracino, R. (2008). Interfacial stress transfer of near surface-mounted FRP-toconcrete joints. Engineering Structures, 30(7), 1861-1868.

Al-Mahmoud, F., Castel, A., \& Francois, R. (2012). Failure modes and failure mechanisms of RC members strengthened by NSM CFRP composites-Analysis of pull-out failure mode. Composites Part B: Engineering, 43(4), 1893-1901.

Ceroni, F., Pecce, M., Bilotta, A., \& Nigro, E. (2012). Bond behavior of FRP NSM systems in concrete elements. Composites Part B: Engineering, 43(2), 99-109.

Chahrour, A., \& Soudki, K. (2005). Flexural response of reinforced concrete beams strengthened with end-anchored partially bonded carbon fiber-reinforced polymer strips. Journal of Composite Construction, 9(2), 170-177.

Choi, H., West, J., \& Soudki, K. (2008). Analysis of the flexural behavior of partially bonded FRP strengthened concrete beams. Journal of Composites for Construction, 12(4), 375-386.

Choi, H., West, J., \& Soudki, K. (2011). Partially bonded nearsurface-mounted CFRP bars for strengthened concrete T-beams. Construction and Building Materials, 25, 2441-2449.

EI-Hacha, R., \& Rizkalla, S. (2004). Near surface-mounted fiber-reinforced polymer reinforcements for flexural strengthening of concrete structures. ACI Structural Journal, 101(5), 717-726.

Fib TG9.3. (2001). Externally bonded FRP reinforcement for $R C$ structures. Technical report on the design and use of externally Bonded Fibre reinforced Polymer Reinforcement (FRP EBR) for reinforced Concrete Structures. International Federation for Structural Concrete.

Hassan, T., \& Rizkalla, S. (2003). Investigation of bond in concrete structures strengthened with near surface mounted carbon fiber reinforced polymer strips. Journal of Composite Construction, 7(3), 248-257.

Jose, S., \& Barros, J. (2007). A pullout test for the near surface mounted CFRP-concrete bond characterization. In Conference of Sociedade Portuguesa de Materials, 13, Porto, Portugal.

Lee, D., Cheng, L., \& Hui, J. (2013). Bond characteristics of various NSM FRP reinforcements in concrete. Journal of Composites for Construction, 17(1), 117-129.

Lorenzis, D., Nanni, L., \& Tegola, L. (2000). Flexural and shear strengthening of reinforced concrete structures with near surface mounted FRP rods. In Proceeding of the 3rd international conference on advanced composite materials in bridges and structures (ACMBS III) (pp. 521-528).

Nanni, A. (2000). FRP reinforcement for bridge structures. Proceedings of structural engineering conference beams. Journal of Composites for Construction (ASCE), 5(1), 12-17.

Rezazadeh, M., \& Barros, J. (2015). Transfer zone of prestressed CFRP reinforcement applied according to NSM technique for strengthening of RC structures. Composites Part B: Engineering, 79(15), 581-594.

Seo, S. (2012). Bond strength of near surface-mounted FRP plate in RC member. Journal of the Korea Concrete Institute, 24(4), 415-422 (in Korean).

Seo, S., Feo, L., \& Hui, D. (2013). Bond strength of near surface-mounted FRP plate for retrofit of concrete structures. Composite Structures, 95, 719-727.

Seracino, R., Jones, N., Ali, M., Page, M., \& Oehlers, D. (2007a). Bond strength of near-surface mounted FRP strip- 
to-concrete joints. Journal of Composite Construction, 11(4), 401-409.

Seracino, R., Raizal, S., \& Oehlers, D. (2007b). Generic debonding resistance of EB and NSM plate-to-concrete joints. Journal of Composite Construction, 11(1), 62-70.

Sharaky, I., Torres, L., Comas, J., \& Barris, C. (2014). Flexural response of reinforced concrete $(\mathrm{RC})$ beams strengthened with near surface mounted (NSM) fibre reinforced polymer (FRP) bars. Composite Structures, 109, 8-22.

Yost, J., Gross, S., Dinehart, D., \& Mildenberg, J. (2007). Flexural behavior of concrete beams strengthened with near surface-mounted CFRP strips. ACI Structural Journal, 104(4), 430-437. 